\title{
Influência da adubação e da cobertura morta na produtividade e no teor de flavonóides de Calendula officinalis L. (Asteraceae)
}

\author{
BORELLA J.C. ${ }^{1,2 *}$; RIBEIRO N.S. ${ }^{1}$; FREATO A.M.R. ${ }^{1}$; MAZZO K.F. ${ }^{1}$; BARBOSA D.M. ${ }^{1}$ \\ ${ }^{1}$ Curso de Ciências Farmacêuticas da Universidade de Ribeirão Preto. Disciplina de Farmacognosia. Av. Costabile \\ Romano, 2201, CEP: 14096-380, Ribeirão Preto - Brasil ${ }^{2}$ Laboratório de Manipulação Farmacêutica da Secretaria \\ Municipal de Saúde de Ribeirão Preto. Rua Dom Luis do Amaral Mouzinho, 3300, CEP: 14090-280, Ribeirão Preto \\ - Brasil *jborella@unaerp.br
}

\begin{abstract}
RESUMO: Desenvolveu-se ensaio de cultivo de Calendula officinalis, variando-se os tipos de adubação e utilização de cobertura morta na observação da produção de inflorescências, droga vegetal e quantificação dos flavonóides presentes nestes materiais. O delineamento experimental adotado foi de blocos casualizados com 3 repetições, em arranjo fatorial de $3 \times 2$, constituído de seis tratamentos, sendo 1. adubação química (100 $\mathrm{kg}$ de $\mathrm{N} \mathrm{ha}{ }^{-1}+50 \mathrm{~kg}$ de $\mathrm{P}$ ha-1); 2 . adubação química + cobertura morta (grama seca - Paspalum notatum); 3. adubação orgânica (esterco bovino curtido $50 \mathrm{t} \mathrm{ha}^{-1}$ ); 4. adubação orgânica + cobertura morta; 5 . sem adubação química ou orgânica + cobertura morta; 6 . sem adubação química ou orgânica e sem cobertura morta (testemunha). Os resultados de número capítulos produzidos, massa seca das inflorescências e massa da droga vegetal foram totalizados após cinco meses do plantio. A quantificação de flavonóides foi realizada através de método espectrofotométrico. Os dados foram analisados estatisticamente (ANOVA/Teste Tukey-Kramer-5\%) e mostraram diferenças significativas $(70 \%$ superior) no número de inflorescências, massa seca das inflorescências e massa da droga vegetal entre o tratamento com adubação orgânica (3) e os tratamentos sem adubação química ou orgânica com cobertura morta (5) e o testemunha (6). As demais comparações, inclusive o teor de flavonóides, entre os diversos tratamentos não resultaram em diferenças significativas.
\end{abstract}

Palavras-chave: Calendula officinalis, flavonóides, adubação, cobertura morta

ABSTRACT: Influence of fertilization and mulching on the productivity and flavonoid content of Calendula officinalis L. (Asteraceae). Calendula officinalis was experimentally grown under field conditions with different fertilization types and mulching in order to evaluate inflorescence production, plant drugs and flavonoid levels. Experimental design was in randomized blocks, with 3 replicates, in a 3x2 factorial arrangement, consisting of six treatments, as follows: 1 . chemical fertilization (100 kg N ha-1 $\left.+50 \mathrm{~kg} \mathrm{P} \mathrm{ha}^{-1}\right) ; 2$. chemical fertilization + mulch (dry grass - Paspalum notatum); 3. organic fertilization (cured bovine manure $50 \mathrm{t} \mathrm{ha}^{-1}$ ); 4 . organic fertilization + mulch; 5. no chemical or organic fertilization + mulch; 6 . no chemical or organic fertilization and no mulch (control). Data regarding number of produced capitula, dry matter of inflorescences and plant drug matter were totaled after five months of planting. Flavonoids were quantified by spectrophotometry. The results were statistically analyzed (ANOVA / Tukey-Kramer test-5\%) and showed significant differences $(70 \%$ higher) for number of inflorescences, inflorescence dry matter and plant drug matter between the treatment with organic fertilization (3) and treatments with no chemical or organic fertilization with mulching (5) and control (6). The remaining comparisons, including flavonoid content, did not result in significant differences among treatments.

Key words: Calendula officinalis, flavonoids, fertilization, mulching

\section{INTRODUÇÃO}

Calendula officinalis, pertencente à família Asteraceae, é herbácia anual, ereta, originária do Egito, das Ilhas Canárias e região do mediterrâneo, se espalhando por vastas regiões do globo. Como planta medicinal tem grande potencial de utilização fazendo parte do elenco de medicamentos produzidos

Recebido para publicação em 17/09/2009

Aceito para publicação em 08/07/2010

Rev. Bras. PI. Med., Botucatu, v.13, n.2, p.235-239, 2011. 
por grande parte de Programas de Fitoterapia no estado de São Paulo (Oliveira et al., 2006) e está contida na lista das espécies medicinais de interesse do Ministério da Saúde para uso no SUS (BRASIL, 2009). É empregada desde antiguidade por árabes, hindus e gregos pelas atividades antiinflamatórias e anti-sépticas de feridas.

O fitoterápico produzido tem ampla gama de utilizações, tais como antiespasmódica, diaforética, antiinflamatória, anti-hemorrágica, emenagoga e antiséptica. Em ensaios in vitro e com animais, apresentou atividade antiinflamatória, imunoestimulante e cicatrizante, além de não apresentar efeitos tóxicos relacionados aos parâmetros bioquímicos e hematológicos, dando respaldo ao emprego tradicional em vários quadros dermatológicos (Alonso, 1998; Lorenzi \& Matos, 2002).

Estudos fitoquímicos concluíram que esta espécie possui no fitocomplexo várias categorias de substâncias, como óleos voláteis, terpenóides, saponinas, carotenóides e flavonóides, sendo que estes últimos podem contribuir no efeito antiinflamatório (Schenkel et al., 1999; Newall et al., 2002; Silva et al., 2005). Desta forma é importante estabelecer procedimentos corretos em relação ao cultivo desta espécie, em cada região do país, priorizando a produção de grande quantidade de droga vegetal com níveis satisfatórios dos princípios ativos, para que esta espécie possa ser utilizada pelos Programas de Fitoterapia com segurança e eficácia. No entanto, o cultivo de calêndula no Brasil ainda foi pouco investigado; sabe-se que se desenvolve bem sob luz. A propagação é feita exclusivamente por sementes e após dois a três meses do semeio, a colheita das inflorescências começa a ser realizada. É pouco exigente a solos, porém necessita de adubação e de boa drenagem. Normalmente consegue-se no cultivo de $C$. officinalis até $720 \mathrm{~kg}$ ha $^{-1}$ de inflorescências secas (Martins et al., 1994), no entanto Vieira et al. (1999) obtiveram produção máxima de $240 \mathrm{~kg} \mathrm{ha}^{-1}$ de inflorescências secas com utilização de $14 \mathrm{t} \mathrm{ha}^{-1}$ de cama de aviário. Martin \& Deo (2000) realizaram estudo sobre a densidade de calêndula nos plantios e concluíram que a quantidade de flores produzidas não era significativamente diferente a partir de 46 plantas $\mathrm{m}^{-2}$, mas declinou com populações menores que esta. A massa de droga vegetal também foi aferida, resultando numa média de $360 \mathrm{~kg} \mathrm{ha}^{-1}$ para uma população de 9 plantas $\mathrm{m}^{-2}$. Moreira et al. (2005) obtiveram aumento da massa na produção de capítulos florais com o incremento de $\mathrm{N}$ e $\mathrm{P}$ ao substrato em experimento desenvolvido em vasos. Leite et al. (2005), em cultivo com várias quantidades de adubação orgânica (esterco bovino e restos de silagem), observaram que a medida recomendada para produção de $C$. officinalis, considerando número de inflorescências e teor de flavonóides $(0,52 \%)$ é de 60 t ha ${ }^{-1}$, no entanto ressaltaram que acima desta proporção pode ocorrer o ataque de pulgões e outros artrópodes à cultura. Berti et al. (2003) cultivaram C. officinalis e concluíram que há a mesma produtividade, em relação aos capítulos florais, independentemente da época de semeadura, embora a variedade da espécie utilizada possa ser fator importante para este quesito. Vieira et al. (2006) obtiveram produção de $142,56 \mathrm{~kg} \mathrm{ha}^{-1}$ de inflorescências secas e concluíram que esta produção independe das cores dos capítulos florais e dos diásporos utilizados no cultivo, porém a maior quantidade de inflorescências $\left(6388,25 \mathrm{mil} \mathrm{ha}^{-1}\right)$ foi obtida de diásporos alados e capítulos laranja. Araújo et al. (2009) utilizaram cobertura morta associada a níveis crescentes de adubação orgânica e obtiveram melhores resultados na produção de inflorescências com $67 \mathrm{t} \mathrm{ha}^{-1}$ de composto orgânico sem utilização de cobertura morta, enquanto que o maior teor de flavonóides $(0,70 \%)$ foi alcançado com $59 \mathrm{t} \mathrm{ha}^{-1} \mathrm{de}$ composto orgânico com utilização da cobertura morta, colhendo-se as inflorescências entre o $60^{\circ}$ ao 90 dia após plantio, mostrando sazonalidade em relação a este quesito. Piccaglia et al. (1999) mostraram que em cultivo para esta espécie, os pigmentos (carotenóides e flavonóides) se diferenciavam muito, numa avaliação em dois anos consecutivos.

Sendo assim, através deste trabalho objetivou-se investigar mais alguns aspectos da produtividade desta espécie comparando diferentes tipos de adubações e fazendo uso ou não de cobertura morta. Os parâmetros analisados foram produção de inflorescências (número e massa seca), produção de droga vegetal (massa) e a quantidade de flavonóides produzidos. Estes dados visam dar um delineamento à conduta para cultivo que poderá ser utilizada para esta espécie medicinal nos Programas de Fitoterapia da Região de Ribeirão Preto-SP.

\section{MATERIAL E MÉTODO}

O experimento relativo ao teste agronômico foi realizado em Campo Experimental da Universidade de Ribeirão Preto - UNAERP, localizado em latitude 2110'42"S, longitude 47ํㅜ'ㄱ'O, altitude de 849 metros e se caracteriza, quimicamente por ser solo de fertilidade média, não apresentando toxicidade por alumínio, topografia não acidentada, clima tropical úmido, com estação chuvosa no verão e seca no inverno. Durante o experimento a temperatura variou de 13 a $33^{\circ} \mathrm{C}$ e a precipitação pluviométrica foi de $523 \mathrm{~mm}$. Exemplares do material foram herborizados e depositados no Herbário de Plantas Medicinais do Laboratório de Biotecnologia da Universidade de Ribeirão Preto, recebendo o número de catalogação HPMU 1326. 
O terreno estava em pousio por um ano e foi capinado, arado, destorroado e levantadas as parcelas manualmente. Foi realizada amostragem de solo na profundidade de $20 \mathrm{~cm}$ para a análise física e química, tendo como resultados para macronutrientes: $\mathrm{pH}=$ 4,9; $\mathrm{P}=45 \mathrm{mg} \mathrm{dm}^{-3} ; \mathrm{Ca}=21 \mathrm{mmol}_{\mathrm{c}} \mathrm{dm}^{-3} ; \mathrm{Mg}=6$ $\mathrm{mmol}_{\mathrm{c}} \mathrm{dm}^{-3} ; \mathrm{K}=1,4 \mathrm{mmol}_{\mathrm{c}} \mathrm{dm}^{-3} ; \mathrm{Al}=0 \mathrm{mmol}_{\mathrm{c}} \mathrm{dm}^{-3}$; $\mathrm{H}+\mathrm{Al}=52 \mathrm{mmol}_{\mathrm{c}} \mathrm{dm}^{-3}$; matéria orgânica $=32 \mathrm{~g} \mathrm{dm}^{-3}$; $\mathrm{V}=35 \%$; micronutrientes: $\mathrm{B}=0,23 \mathrm{mg} \mathrm{dm}^{-3} ; \mathrm{Cu}=$ $4,2 \mathrm{mg} \mathrm{dm}^{-3} ; \mathrm{Fe}=29 \mathrm{mg} \mathrm{dm}^{-3} ; \mathrm{Mn}=6,1 \mathrm{mg} \mathrm{dm}^{-3}$; $\mathrm{Zn}=1,5 \mathrm{mg} \mathrm{dm}^{-3}$; Granulometria: Areia total $=217 \mathrm{~g}$ $\mathrm{kg}^{-1}$; Areia grossa $=140 \mathrm{~g} \mathrm{~kg}^{-1}$; Areia fina $=77 \mathrm{~g} \mathrm{~kg}^{-1}$ Silte $=600 \mathrm{~g} \mathrm{~kg}^{-1} ;$ Argila $=184 \mathrm{~g} \mathrm{~kg}^{-1}$. Procedimentos de calagem e elevação de saturação de bases a 50\% foram realizados.

A semeadura foi realizada em junho de 2007 , utilizando sementes da variedade Bonina Dobrada (Isla Pak), em bandejas plásticas contendo terra, composto orgânico e areia, na proporção de 1:1:1 e foram protegidas do sol através de sombrite e irrigadas diariamente. Foram utilizados 3 diásporos por unidade da bandeja e após 15 dias da emergência as mudas sofreram desbaste, deixando-se a planta mais vigorosa. O transplante para o local definitivo foi realizado em julho de 2007, quando as mudas atingiram cerca de $5 \mathrm{~cm}$ de altura e foram distribuídas na parcela com espaçamento de $0,3 \mathrm{~m}$ entre plantas e de $0,5 \mathrm{~m}$ entre as fileiras. Foi utilizado sistema de aspersão para irrigação uma vez ao dia, quando necessária. O delineamento experimental adotado foi de blocos casualizados com 3 repetições, em arranjo fatorial de $3 \times 2$, constituído de seis tratamentos. Cada parcela mediu $2 \mathrm{~m} \times 3 \mathrm{~m}\left(6 \mathrm{~m}^{2}\right)$, contendo cinco fileiras simples com vinte e cinco plantas (4,2 plantas $\left.\mathrm{m}^{-2}\right)$.

Os tratamentos foram 1. adubação química (100 kg de $\mathrm{N} \mathrm{ha}^{-1}+50 \mathrm{~kg}$ de $\mathrm{P}$ ha-1); 2. adubação química ( $100 \mathrm{~kg}$ de $\mathrm{N} \mathrm{ha}^{-1}+50 \mathrm{~kg}$ de $\left.\mathrm{P} \mathrm{ha}^{-1}\right)+$ cobertura morta de grama seca (Paspalum notatum); 3. adubação orgânica (esterco bovino curtido 50 tha-1); 4 . adubação orgânica (esterco bovino curtido 50 t ha $^{-1}$ ) + cobertura morta de grama seca (Paspalum notatum); 5. sem adubação química ou orgânica + cobertura morta de grama seca (Paspalum notatum); 6 . sem adubação química ou orgânica e sem cobertura morta (testemunha).

A distribuição dos tratamentos entre as parcelas foi feita de maneira aleatória, por sorteio. $\mathrm{O}$ esterco bovino curtido foi aplicado a lanço nos canteiros e incorporado com enxada, oito dias antes do transplante. O fósforo foi aplicado de uma só vez no plantio das mudas e o nitrogênio foi parcelado em duas doses iguais, sendo a primeira no plantio e a outra após trinta dias. Tratos culturais como capina e reposição da cobertura morta, formando uma camada de cinco centímetros sobre o solo, foram feitos quando necessários. As coberturas mortas foram produzidas através do cultivo, colheita e secagem de Paspalum notatum (grama-batatais). $O$ primeiro depósito de cobertura morta no solo foi realizado juntamente com o transplante das mudas. Os adubos foram uréia, como fonte de nitrogênio e superfosfato simples $\left(\mathrm{P}_{2} \mathrm{O}_{5}\right)$, como fonte de fósforo. $\mathrm{A}$ distribuição das parcelas no ensaio agronômico foi realizada por sorteio.

A colheita foi iniciada setembro e concluída em dezembro de 2007. Os capítulos foram colhidos com tesoura de poda, quando as flores tubulosas estavam na antese e as flores liguladas estavam na horizontal, em colheitas de dois em dois dias. As inflorescências foram conservadas em sacos de papel e depositadas em ambiente a $35^{\circ} \mathrm{C}$ (estufa de ar circulante) até que elas atingissem o valor de $12 \% \mathrm{p} /$ $\mathrm{p}$ de umidade, ou menos, conforme preconiza monografia desta espécie na Farmacopéia Brasileira 4a ed. (2001) e então foram pesados. Os dados coletados foram o número de capítulos e massa seca das inflorescências por parcela. Após secagem e pesagem das inflorescências, estas foram submetidas à manipulação para que fossem separadas delas o que a Farmacopéia Brasileira 4a ed. (2001) preconiza como droga para C. officinalis: "A droga vegetal consiste das flores liguladas inteiras ou trituradas, acompanhadas de escassas flores tubulosas, separadas do receptáculo e das brácteas involucrais, secas". Depois da separação, a droga vegetal foi novamente pesada e moída em moinho de facas, obtendo-se o material pulverizado com granulometria menor ou igual a $800 \mathrm{~mm}(0,8 \mathrm{~mm}), 0$ qual foi submetido à análise espectrofotométrica do teor de flavonóides totais (calculados como Hiperosídeos), como descrito na Farmacopéia Brasileira 4a ed. (2001). Todos os dados obtidos foram comparados estatisticamente (análise de variância ANOVA e teste de comparação múltipla de TukeyKramer ao nível de $5 \%$ de probabilidade).

\section{RESULTADO E DISCUSSÃO}

Os resultados foram sumarizados na Tabela 1 e mostram diferenças significativas entre 0 tratamento 3 (adubação orgânica) quando comparado com os tratamentos 5 (sem adubação química ou orgânica + cobertura morta) e 6 (testemunha), em relação ao número, massa seca das inflorescências e massa de droga vegetal (diferenças acima de 70\%). As demais comparações entre os diversos tratamentos e os parâmetros avaliados não resultaram em diferenças significativas. Naqueles tratamentos onde se utilizou cobertura morta resultaram em produções de número, massa seca das inflorescências e massa de droga vegetal, estatisticamente iguais, e em valores absolutos, abaixo daqueles em que os mesmos tratamentos foram realizados sem cobertura, inclusive quando

Rev. Bras. PI. Med., Botucatu, v.13, n.2, p.235-239, 2011. 
TABELA 1. Média dos valores obtidos do número de inflorescências, massa seca das inflorescências, massa da droga vegetal e teor de flavonóides no ensaio de agronômico de Calendula officinalis.

\begin{tabular}{|c|c|c|c|c|}
\hline Tratamentos & $\begin{array}{c}\text { Nú mero de } \\
\text { inflorescências } \\
(x 1000) \mathrm{ha}^{-1}\end{array}$ & $\begin{array}{c}\text { Massa seca das } \\
\text { inflorescências } \\
\left(\mathrm{kg} \mathrm{ha}^{-1}\right)\end{array}$ & $\begin{array}{c}\text { Massa da droga } \\
\text { vegetal } \\
\left(\mathrm{kg} \mathrm{ha}^{-1}\right)\end{array}$ & $\begin{array}{c}{ }^{*} \text { Teor de } \\
\text { flavonóides totais } \\
(\% \mathrm{~m} / \mathrm{m})\end{array}$ \\
\hline $\begin{array}{l}\text { 1. Adubação } \\
\text { química }\end{array}$ & $\begin{array}{c}3219 \mathrm{bc} \\
(796,37 ; 25,75)\end{array}$ & $\begin{array}{c}667,75 b c \\
(185,46 ; 27,77)\end{array}$ & $\begin{array}{c}176,48 \mathrm{bc} \\
(55,76 ; 31,59)\end{array}$ & $\begin{array}{c}0,63 a \\
(0,01 ; 1,84)\end{array}$ \\
\hline $\begin{array}{l}\text { 2. Ad. química + } \\
\text { cobertura morta }\end{array}$ & $\begin{array}{c}2219 b c \\
(601,58 ; 27,10)\end{array}$ & $\begin{array}{c}475,83 b c \\
(144,98 ; 30,47)\end{array}$ & $\begin{array}{c}137,11 \mathrm{bc} \\
(50,99 ; 37,19)\end{array}$ & $\begin{array}{c}0,79 a \\
(0,13 ; 16,93)\end{array}$ \\
\hline $\begin{array}{l}\text { 3. Adubação } \\
\text { orgânica }\end{array}$ & $\begin{array}{c}4449 \mathrm{ac} \\
(1878,67 ; 42,23)\end{array}$ & $\begin{array}{c}806,21 \mathrm{ac} \\
(346,25 ; 42,95)\end{array}$ & $\begin{array}{c}213,80 \mathrm{ac} \\
(102,08 ; 47,75)\end{array}$ & $\begin{array}{c}0,74 a \\
(0,05 ; 7,15)\end{array}$ \\
\hline $\begin{array}{l}\text { 4. Ad. orgânica + } \\
\text { cobertura morta }\end{array}$ & $\begin{array}{c}3876 \mathrm{bc} \\
(1406,70 ; 36,30)\end{array}$ & $\begin{array}{c}733,43 \mathrm{bc} \\
(234,69 ; 32,00)\end{array}$ & $\begin{array}{c}206,80 \mathrm{bc} \\
(64,03 ; 30,96)\end{array}$ & $\begin{array}{c}0,70 a \\
(0,14 ; 21,00)\end{array}$ \\
\hline $\begin{array}{l}\text { 5. Cobertura } \\
\text { morta }\end{array}$ & $\begin{array}{c}909 b \\
(537,85 ; 59,18)\end{array}$ & $\begin{array}{c}178,71 b \\
(95,40 ; 53,38)\end{array}$ & $\begin{array}{c}53,28 b \\
(28,25 ; 53,01)\end{array}$ & $\begin{array}{c}0,69 a \\
(0,10 ; 13,83)\end{array}$ \\
\hline 6. Testemunha & $\begin{array}{c}1084 b \\
(690,26 ; 64,67)\end{array}$ & $\begin{array}{c}233,37 b \\
(144,88 ; 62,08)\end{array}$ & $\begin{array}{c}62,17 b \\
(41,46 ; 66,69)\end{array}$ & $\begin{array}{c}0,65 a \\
(0,14 ; 21,00)\end{array}$ \\
\hline Desvio padrão & 1464,85 & 264,49 & 70,44 & 0,06 \\
\hline $\mathrm{CV}(\%)$ & 55,78 & 51,27 & 49,74 & 8,46 \\
\hline
\end{tabular}

$n=3 ; p<0,05$ - ANOVA seguido pelo teste de comparações múltiplas de Tukey-Kramer. Médias seguidas pelas mesmas letras minúsculas, nas colunas, não diferem estatisticamente entre si. Números entre parênteses, abaixo das médias, referem-se respectivamente, ao desvio padrão e coeficiente de variação x 100. *Teor de flavonóides totais estimados como Hiperosídeos. CV(\%): Coeficiente de Variação (x 100)

comparado com o tratamento testemunha (6), sugerindo que, para esta espécie, este tipo de cobertura não melhora a produtividade, nem o teor de flavonóides.

Este resultado está em desacordo com aquele apresentado por Araújo et al. (2009), onde a cobertura morta foi eficiente para elevar os teores dos flavonóides numa fase de colheita entre o 60 e o 90응 dia após plantio. Provavelmente, estes comportamentos diversos podem estar relacionados com diferenças na composição do solo e fatores ambientais presentes nestes experimentos. A adubação química utilizada, contendo $\mathrm{Ne} \mathrm{P}$, fazendo uso ou não de cobertura morta, teve comportamento estatístico semelhante àquele do tratamento testemunha (6). Desta forma este tipo de tratamento não se mostrou tão produtivo quanto àquele que se utilizou adubação orgânica (tratamento 3) que produziu uma massa de inflorescências secas $\left(806,29 \mathrm{Kg} \mathrm{ha}{ }^{1}\right)$, superior àquelas citadas por Martins et al. (1994) (720 $\mathrm{Kg} \mathrm{ha}^{-1}$ ) e Vieira et al. (1999; 2006) (240 e 142,56 kg ha $^{-1}$, respectivamente). A produção de droga vegetal com a adubação orgânica (tratamento 3) foi de 213,80 $\mathrm{kg} \mathrm{ha}^{-1}$ (4,2 plantas $\mathrm{m}^{-2}$ ), abaixo dos $360 \mathrm{~kg} \mathrm{ha}^{-1}$ descritos por Martin \& Deo (2000), mas mantendo boa proporcionalidade, pois esta produção foi obtida cultivando calêndula onde a densidade era de 9 plantas $\mathrm{m}^{-2}$.
Em relação aos flavonóides na droga vegetal, os valores variaram entre 0,65 a $0,79 \%(\mathrm{~m} / \mathrm{m}$ calculados como Hiperosídeos) e não foram influenciados pelo tipo de adubação ou pelo uso de cobertura morta. Estes valores, apesar de significativamente iguais entre os tratamentos testados, estão bem acima do mínimo exigido pela Farmacopéia Brasileira $4^{a}$ ed. (2001) que preconiza $0,40 \%$. Os valores encontrados neste experimento para teor de flavonóides são superiores àqueles descritos por Leite et al. (2005) (0,52\%) usando $60 \mathrm{t}$ ha $^{-1}$ esterco bovino e restos de silagem. O teor de flavonóides doseado por Araújo et al.(2009) foi 0,70\% com utilização de 59 t ha-1 de composto orgânico e com utilização de cobertura morta. Níveis semelhantes de flavonóides $(0,74 \%)$ foram obtidos neste experimento (tratamento 3 - esterco bovino curtido $50 \mathrm{t} \mathrm{ha}^{-1}$ ), sem utilização de cobertura morta.

Deste modo, a partir da conduta e dos dados obtidos neste experimento podemos admitir que boas produções de droga vegetal de $C$. officinalis $(\sim 210 \mathrm{~kg}$ ha $\left.^{-1}\right)$, com teores acima dos mínimos exigidos $(\sim 0,70 \% \mathrm{~m} / \mathrm{m})$ possam ser realizadas na região de Ribeirão Preto - SP utilizando-se adubação orgânica (esterco bovino curtido $50 \mathrm{t} \mathrm{ha}^{-1}$ ), sem necessidade de cobertura do solo com grama seca. Esta conduta poderá ser utilizada pelos Programas de Fitoterapia desta região que visam estabelecer plantios para 
produção de insumos de fitoterápicos que serão utilizados na Rede Pública de Saúde (SUS).

\section{AGRADECIMENTO}

Fundação de Amparo à Pesquisa do Estado de São Paulo (FAPESP), Conselho Nacional de Desenvolvimento Científico e Tecnológico (CNPq) e Ministério da Saúde pelo apoio financeiro para realização deste projeto.

\section{REFERÊNCIA}

ALONSO, J.R. Tratado de Fitomedicina. Buenos Aires: Isis Ediciones SRL, 1998. p.327-31.

ARAÚJO, C.B.O. et al. Uso da adubação orgânica e cobertura morta na cultura da calêndula (Calendula officinalis L.). Revista Brasileira de Plantas Medicinais, v.11, n.2, p.117-23, 2009.

BERTI, M.D. et al. Influencia de la fecha de siembra y de la semilla en el rendimiento de capítulos de Calendula officinalis L. durante dos temporadas en Chillán. Agricultura Técnica, v.63, n.1, p.3-9, 2003.

BRASIL. Ministério da Saúde. Secretaria de Vigilância em Saúde. 2009. Disponível em: <http://portal.saude. gov.br/ portal/arquivos/pdf/RENISUS.pdf>. Acesso em: 25 fev.2009. FARMACOPÉIA BRASILEIRA. 4.ed. São Paulo: Atheneu, 2001. Parte II. Fascículo 3. Monografia 134.

LEITE, G.L.D. et al. Níveis de adubação orgânica na produção de calêndula e artrópodes associados. Arquivos do Instituto de Biologia, v.72, n.2, p.227-33, 2005. LORENZI, H.; MATOS, F.J.A. Plantas medicinais do Brasil: nativas e exóticas. Nova Odessa: Instituto Plantarum, 2002. 543p.

MARTIN, R.J.; DEO, B. Effect of plant population on calendula (Calendula officinalis L.) flower production.
New Zealand Journal of Crop and Horticultural Science, v.28, p.37-44, 2000.

MARTINS, E.R. et al. Plantas medicinais. Viçosa: Universidade Federal de Viçosa, Imprensa Universitária, 1994. 89p.

MOREIRA, P.A. et al. Desenvolvimento vegetativo e teor foliar de macronutrientes da calêndula (Calendula officinalis L.) adubada com nitrogênio e fósforo. Revista Brasileira de Plantas Medicinais, v.8, n.1, p.18-23, 2005. NEWALL, C.A.; ANDERSON, L.A.; PHILLIPSON, J.D. Fitoterapia plantas medicinais: guia para profissional de saúde. São Paulo: Editorial Premier, 2002. p.57-8.

OLIVEIRA, M.J.R.; SIMÕES, M.J.S.; SASSI, C.R.R. Fitoterapia no sistema de saúde pública (SUS) no Estado de São Paulo, Brasil. Revista Brasileira de Plantas Medicinais, v.8, n.2, p.39-41, 2006.

PICCAGLIA, R. et al. Effects of harvesting date and climate on the flavonoid and carotenoid contents of Marigold (Calendula officinalis L.) Flavour and Fragance Journal, v.12, n.2, p.85-90, 1999.

SCHENKEL E.P.; GOSMANN, G.; ATHAYDE, M.L. Saponinas. In: SIMÕES, C.M.O. et al. (Orgs.). Farmacognosia da planta ao medicamento. Porto Alegre/Florianópolis: Editora da UFRGS/UFSC, 1999. p.597-622.

SILVA, E.J.R. et al. Avaliação do tratamento subcrônico com extrato hidroalcóolico de Calendula officinalis $\mathrm{L}$. sobre os parâmetros bioquímicos e hematológicos em ratas Wistar. Revista Brasileira de Farmacognosia, v.15, n.2, p.88-93, 2005.

VIEIRA, M.C. et al. Crescimento e produção de capítulos de Calendula officinalis L., em função de cama-de-aviário semi-decomposta e de fósforo. Revista Brasileira de Plantas Medicinais, v.1, n.2, p.45-52, 1999.

VIEIRA, M.C. et al. Crescimento e produção de biomassa de calêndula (Calendula officinalis L.) proveniente de dois tipos de diásporos e duas colorações de capítulos florais. Revista Brasileira de Plantas Medicinais, v.8, n.4, p.193-7, 2006. 